\title{
Newborn hearing screening programme in Belgium: a consensus recommendation on risk factors
}

Bénédicte Vos ${ }^{1,2,3^{*}}$, Christelle Senterre ${ }^{1}$, Raphaël Lagasse ${ }^{2}$, SurdiScreen Group and Alain Levêque ${ }^{1,2,3}$

\begin{abstract}
Background: Understanding the risk factors for hearing loss is essential for designing the Belgian newborn hearing screening programme. Accordingly, they needed to be updated in accordance with current scientific knowledge. This study aimed to update the recommendations for the clinical management and follow-up of newborns with neonatal risk factors of hearing loss for the newborn screening programme in Belgium.

Methods: A literature review was performed, and the Grading of Recommendations, Assessment, Development and Evaluation (GRADE) system assessment method was used to determine the level of evidence quality and strength of the recommendation for each risk factor. The state of scientific knowledge, levels of evidence quality, and graded recommendations were subsequently assessed using a three-round Delphi consensus process (two online questionnaires and one face-to-face meeting).

Results: Congenital infections (i.e., cytomegalovirus, toxoplasmosis, and syphilis), a family history of hearing loss, consanguinity in (grand)parents, malformation syndromes, and foetal alcohol syndrome presented a 'high' level of evidence quality as neonatal risk factors for hearing loss. Because of the sensitivity of auditory function to bilirubin toxicity, hyperbilirubinaemia was assessed at a 'moderate' level of evidence quality. In contrast, a very low birth weight, low Apgar score, and hospitalisation in the neonatal intensive care unit ranged from 'very low' to 'low' levels, and ototoxic drugs were evidenced as 'very low'. Possible explanations for these 'very low' and 'low' levels include the improved management of these health conditions or treatments, and methodological weaknesses such as confounding effects, which make it difficult to conclude on individual risk factors. In the recommendation statements, the experts emphasised avoiding unidentified neonatal hearing loss and opted to include risk factors for hearing loss even in cases with weak evidence. The panel also highlighted the cumulative effect of risk factors for hearing loss.
\end{abstract}

Conclusions: We revised the recommendations for the clinical management and follow-up of newborns exhibiting neonatal risk factors for hearing loss on the basis of the aforementioned evidence-based approach and clinical experience from experts. The next step is the implementation of these findings in the Belgian screening programme.

Keywords: Neonate, Risk factor, Screening, Hearing loss, GRADE, Consensus method

\footnotetext{
* Correspondence: benevos@ulb.ac.be

${ }^{1}$ Research Center Epidemiology, Biostatistics and Clinical Research, Université

libre de Bruxelles (ULB), School of Public Health, Route de Lennik 808,

Brussels 1070, Belgium

${ }^{2}$ Research Center Health Policy and Systems - International Health, Université

libre de Bruxelles (ULB), School of Public Health, Route de Lennik 808,

Brussels 1070, Belgium

Full list of author information is available at the end of the article
}

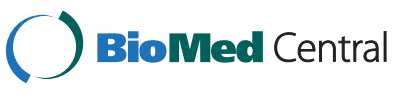

(c) 2015 Vos et al. Open Access This article is distributed under the terms of the Creative Commons Attribution 4.0 International License (http://creativecommons.org/licenses/by/4.0/), which permits unrestricted use, distribution, and reproduction in any medium, provided you give appropriate credit to the original author(s) and the source, provide a link to the Creative Commons license, and indicate if changes were made. The Creative Commons Public Domain Dedication waiver (http://creativecommons.org/publicdomain/zero/1.0/) applies to the data made available in this article, unless otherwise stated. 


\section{Background}

The prevalence of bilateral hearing loss is substantial, particularly in neonates admitted to the neonatal intensive care unit (NICU) who frequently present with risk factors for hearing loss. The prevalence of significant bilateral hearing loss in this group is $1-3 \%$, which is 10 times higher than that in the well-baby nursery population [1]. Furthermore, early intervention in hearing-impaired children (aged 6 months or earlier) improved their language and speech outcomes as well as their socioemotional development [2-4]. Therefore, universal newborn hearing screening is widely recommended [5-7] and implemented by governments or mother and child health agencies.

Follow-up on toddlers' hearing to diagnose potential delayed-onset or progressive hearing loss in childhood is a major issue. In 2007, the Joint Committee on Infant Hearing ( $\mathrm{JCIH})$ released a unique list of risk indicators associated with congenital/neonatal hearing loss and delayed-onset/acquired or progressive hearing loss [6]. The JCIH recommends monitoring hearing, and speech and language skills of all infants as well as performing an audiological assessment at least once by 24-30 months of age in infants presenting with one or more risk indicators from this list. Most newborn hearing screening programmes and other recommendation statements refer to the statements of the JCIH. However, some authors have recently highlighted that the literature does not corroborate some risk indicators listed by the $\mathrm{JCIH}$, especially with respect to their relationship with postnatal hearing loss $[8,9]$.

As in other regions, in Belgium, knowing the risk factors for hearing loss is essential for designing a newborn hearing screening programme with different organisations and tests. According to the programme of the Fédération Wallonie-Bruxelles (FWB, the French-speaking area of Belgium) launched in 2006, different protocols and neonatal hearing tests are performed depending on the presence or absence of particular risk factors; in their absence, an automated screening test of the cochlea is performed, whereas an audiological assessment is recommended in the presence of risk factor(s). This audiological assessment comprises diagnostic tests that evaluate the entire auditory function, including that of the central auditory system. The identification of risk factors directs neonates to the appropriate clinical pathway and thus is essential.

Since the beginning of the newborn hearing screening programme in the FWB, the risk factors were based on the JCIH 2000 Position Statement [10] and the clinical experience of professionals from the FWB. However, this list of risk factors must be updated. Clinicians, specifically otorhinolaryngologists and paediatricians, initially requested this update because the removal, addition, and/or clarification of some risk factors were required in their clinical practice. New scientific findings and studies were subsequently published, leading to the updated JCIH Position Statement in 2007 [6].

The present study aimed to update the recommendation for the clinical management of newborns with neonatal risk factors for hearing loss on the basis of current scientific knowledge. The recommendations were obtained by performing a literature review and then grading the evidence. Finally, the recommendations were validated by the consensus of a panel of experts in the context of the newborn hearing screening programme in the FWB. We also present the recommended follow-up regime for newborns with neonatal risk factors for hearing loss.

\section{Methods}

A consensus research procedure was used to update the clinical management of newborns exhibiting neonatal risk factors for hearing loss in the newborn hearing screening programme in the FWB (Fig. 1).

\section{Research context}

To define the research context, objectives and research questions were clarified using the population, intervention, comparison, and outcomes (PICO) tool. This framework was applied to each risk factor for hearing loss used in the newborn hearing screening programme in the FWB (Table 1).

\section{Literature review}

Between September 2014 and December 2014, we reviewed the literature from the last 15 years for each risk factor on the original list, and aimed to answer two specific questions for each risk factor: (1) is it scientifically pertinent to consider it as a risk factor for hearing loss in the newborn hearing screening programme? and (2) how is the risk factor defined?

We reviewed the PubMed database, the academic library of our institution, and the Cochrane Library for articles in English and French. The following search terms were used: ['hearing loss' OR 'hearing impairment' OR 'deafness'] AND ['newborn' OR 'neonatal']. In addition, each risk factor was searched (using Medical Subject Headings (MeSH) terms or not). To the extent possible, the literature review was limited to the last 15 years to avoid the effects of changes in healthcare. Nonetheless, if the literature review results were insufficient, the search period was prolonged and the literature research was extended to 'neurodevelopmental outcomes' on the condition that the articles in question investigated hearing loss. In cases in which few relevant papers were found, bibliographies were used to find other references. Review articles were included, but animal model studies were excluded. The literature review revealed three 


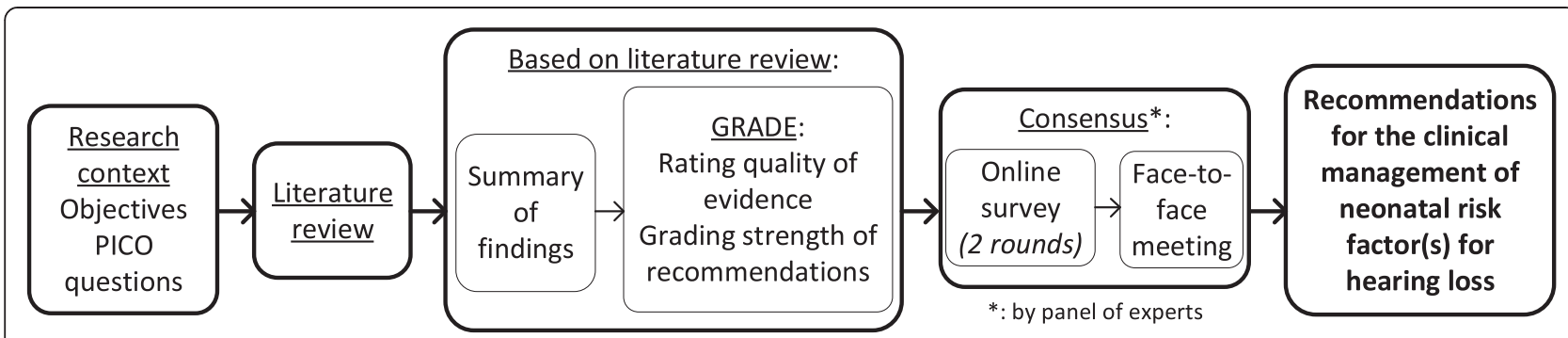

Fig. 1 Flowchart of the methodological process

potential risk factors not included in the original list that were included in the analysis: congenital diaphragmatic hernia, extracorporeal membrane oxygenation, and inhaled nitric oxide.

When available in the selected papers, scientific information about follow-up and postnatal hearing loss was also reviewed for the risk factors from the original list (i.e., what kinds of tests and timing are necessary?). To ensure all risk factors were included in the list of the FWB, a global literature review was performed using the search terms 'neonatal hearing loss' and 'postnatal hearing loss'. We also searched the web to identify specific documents from other newborn hearing screening programmes (i.e., grey literature).

Table 1 Original neonatal risk factors for hearing loss in the newborn hearing screening programme

\begin{tabular}{l} 
Congenital infections: \\
In utero infection due to cytomegalovirus, toxoplasmosis, herpes, \\
rubella, and syphilis \\
Genetics of hearing loss: \\
Family history of hereditary hearing loss \\
Consanguinity in the first degree (i.e., parents are cousins) \\
Head or neck malformations, and by extension each polymalformation \\
syndrome known to include hearing loss \\
Maternal intoxication during pregnancy: \\
Poisoning (alcohol or drugs) by the mother during pregnancy \\
Specific conditions of the neonate: \\
Gestational age $<36$ weeks and/or birth weight $<1,500 \mathrm{~g}$ \\
Apgar score of $0-6$ at 5 min \\
Exchange transfusion (see reference curves) (hyperbilirubinaemia \\
or Rhesus incompatibility) \\
Medical care: \\
Neonatal intensive care unit stay $>5$ days \\
Newborn ototoxic medication \\
Assisted ventilation $\geq 24 \mathrm{~h}$ \\
Particular diseases: \\
Neurologic disease of the newborn (e.g., meningitis, etc.) \\
Endocrine disease of the newborn (e.g., thyroidal disease, etc.) \\
\hline
\end{tabular}

\section{Level of evidence}

The main findings from each paper were summarised in a table using the same framework for all risk factors. The state of the scientific knowledge was subsequently rated according to the Grading of Recommendations, Assessment, Development and Evaluation (GRADE) system [11]. The quality of evidence of each risk factor from the screening programme as a risk factor for hearing loss was rated on the basis of the summary of scientific literature. The level of quality was rated as high, moderate, low, or very low. Considering the PICO questions and study objectives, the studies reviewed were mostly observational, starting at a 'low' level of quality. Nevertheless, the rating can be upgraded or downgraded according to the methodological elements of the studies [12, 13].

\section{Strength of the recommendations}

Recommendations were formulated on the basis of the literature review, quality of evidence, confidence in the 'balance between desirable and undesirable effects' of the management strategies, required resources, and patients' values and preferences (based on experts' experience) [14]. Each recommendation was graded as 'recommend' (strong) or 'suggest' (weak) [14]. Regarding the hearing screening programme, 'audiological assessment' referred to detailed hearing tests that should be implemented in the presence of risk factors for hearing loss. Conversely, 'screening test' referred to the mass screening test performed in the absence of a given neonatal risk factor.

\section{Consensus method}

The Delphi consensus method was used. Experts in paediatrics, otorhinolaryngology, or newborn hearing screening were recruited to participate in the panel of experts. The final panel was comprised of six otorhinolaryngologists (from university or non-university hospitals or hearing rehabilitation centres), three paediatricians (from hospitals or the Mother and Child Health Agency), and one neurophysiologist. These experts were not mandated by a government organisation and had no competing interests related to this project; their sole motivation was to improve the newborn hearing screening programme 
in accordance with clinical realities and current medical knowledge.

The consensus process was conducted between January 2015 and April 2015 in three rounds: two rounds of online questionnaires and one face-to-face meeting. The first online questionnaire aimed to validate the state of scientific knowledge, the rated evidence for each neonatal risk factor, and the proposed graded recommendations. All pertinent scientific literature and the aforementioned summary of the scientific papers were available for the panel of experts. The online surveys were conducted using SurveyMonkey ${ }^{\circ}$, and responses were coded on a Likert scale from 1 to 5 (strongly agree, agree, neutral, disagree, and strongly disagree, respectively). A consensus was reached when at least two-thirds of the panel agreed or disagreed, and when the mean Likert score was $\leq 2$ or $\geq 4$ [15]. A second questionnaire was administered for discordant items related to recommendations; nonconsensual states of scientific knowledge and rated evidence were adapted. The second online questionnaire used stricter criteria with a narrow Likert scale from 1 to 3 (agree, neutral, and disagree, respectively), or only two answer options were provided. The advantage of the online survey was that each expert had the opportunity to independently express his/her opinion. Finally, the panel of experts discussed persistent discordances from the second online questionnaire during the face-to-face meeting to reach a final consensus.

\section{Ethical concern}

The ethical approval and informed consent are not necessary according to Belgian regulations (the clinical research Act - 2004 and the privacy Act - 1998).

\section{Results}

The rated levels of evidence and graded recommendations for each risk factor are summarised in Table 2.

\section{Congenital infections}

The prevalence of sensorineural hearing loss was higher in neonates with congenital cytomegalovirus (CMV) than those without risk factors for hearing impairment. Observational studies (i.e., cohort and case-control studies) reported a strong association in neonates between hearing impairment and congenital CMV infection regardless of whether the infection is symptomatic or asymptomatic at birth $[16,17]$. Moreover, studies following children during infancy also reported late-onset or fluctuating hearing loss, highlighting the need for audiological follow-up of infants with congenital CMV during childhood [16-18]. Antiviral therapy in neonates with congenital CMV has improved developmental and hearing outcomes but has not resulted in total recovery [19-21]. Antiviral therapy is recommended for symptomatic neonates but not all congenital CMV-infected neonates.

Similarly, congenital toxoplasmosis, syphilis, and rubella are reportedly associated with neonatal hearing impairment [22-27]. Nowadays, treatments for congenital toxoplasmosis and syphilis, and rubella vaccine are administered. Current results show no evidence for the association between sensorineural hearing loss in neonates with congenital toxoplasmosis or syphilis when adequately treated [25, 28-31]. Nevertheless, follow-up evaluation of hearing is recommended even for adequately treated cases of toxoplasmosis or syphilis [25, 29]. Furthermore, infants with congenital rubella syndrome have an elevated risk of hearing impairment. Therefore, neonatal hearing evaluation and follow-up during childhood are required for rubella-infected newborns [27, 32]. Nonetheless, widespread rubella vaccination has dramatically reduced the incidence of the disease. Consequently, hearing impairment due to congenital rubella is now rare. However, the small number of cases is an issue in some studies, resulting in low statistical power.

A systematic literature review evaluated the association between congenital herpes infections and sensorineural hearing loss in neonates: only three studies were identified, and limited evidence supports the assumption that herpes simplex virus infection is a cause of sensorineural hearing loss [33]. Methodological limitations such as inaccurate audiological information and the timing of infection, and the imprecise timing of tests limit the strength of this association.

\section{Recommendations}

The panel of experts recommends performing audiological assessment during the neonatal period for newborns with congenital CMV, toxoplasmosis, rubella (i.e., congenital rubella syndrome), or syphilis infection.

The panel of experts recommends performing a hearing screening test on newborns with congenital herpes simplex virus.

The panel of experts clarifies that congenital infection means that the newborn is infected, not merely maternal seroconversion during pregnancy. Neonatal infection should be identified by blood test (i.e., serologic confirmation of toxoplasmosis, rubella, and syphilis) or urine test (i.e., CMV infection) according to the infection.

This recommendation places high value on the level of evidence of the risk factor for hearing loss and low value on the treatment status of the neonate.

\section{Genetics of hearing loss: family history, consanguinity, syndromes, and malformations}

In the literature, a family history of hearing loss is often analysed with consanguinity [34-36]. However, the state of genetics-related knowledge suggests a 
Table 2 Level of the quality of evidence and strength of the recommendation for each risk factor

\begin{tabular}{|c|c|c|}
\hline Risk factor & Quality of evidence & Strength of recommendation \\
\hline Congenital cytomegalovirus & High & Strong \\
\hline Congenital toxoplasmosis & High & Strong \\
\hline Congenital syphilis & High & Strong \\
\hline Congenital rubella & High & Strong \\
\hline Congenital herpes & Very low & Strong ${ }^{a}$ \\
\hline Family history of hearing loss & Moderate & Strong \\
\hline Consanguinity & Moderate & Strong \\
\hline Malformations and syndromes associated with hearing loss & High & Strong \\
\hline Malformations of the pinnae (isolated) & Low & Weak \\
\hline Maternal intoxication: foetal alcohol syndrome & Moderate & Strong \\
\hline Maternal intoxication: drug abuse & Very low & Strong ${ }^{a}$ \\
\hline Very low birth weight & Very low & Strong \\
\hline Birth asphyxia/Apgar score & Low & Strong \\
\hline Hyperbilirubinaemia & Moderate & Strong \\
\hline Neonatal intensive care unit stay & Very low & Weak \\
\hline Assisted ventilation & Very low & Weak \\
\hline Ototoxic drugs: aminoglycosides & Very low & Weak \\
\hline Ototoxic drugs: loop diuretics & Very low & Weak \\
\hline Extracorporeal membrane oxygenation & Moderate & Strong \\
\hline Congenital diaphragmatic hernia & Very low & $--^{b}$ \\
\hline Inhaled nitric oxide & Very low & $--^{b}$ \\
\hline Neurologic disease: meningitis & Moderate & Strong ${ }^{c}$ \\
\hline Neurologic disease: intraventricular haemorrhage & Very low & Weak \\
\hline Congenital hypothyroidism & Moderate & Strong \\
\hline
\end{tabular}

${ }^{a}$ Strongly recommended to not consider this as a risk factor for hearing loss

${ }^{\mathrm{b}}$ The panel decided to formulate no specific recommendation; because of the medical condition, ventilation will be performed (see recommendation for assisted ventilation)

'On the basis of their clinical experience, the panel decided to recommend an audiological assessment for newborns who need a neurologic consultation (e.g., convulsion, hypotonia, swallowing/feeding difficulties, or cranial nerve palsy)

family history as a potential risk factor of hearing loss in infants [37-39], particularly postnatal hearing loss was recently demonstrated [40]. The literature clearly demonstrates that the degree of parental consanguinity is significantly and directly associated with the prevalence of hearing loss in children [34, 41-43]. Furthermore, knowledge on genetics also indicates that specific congenital syndromes are associated with hearing loss; multiple websites and reviews have taken inventory of such conditions [44-46]. Isolated malformations of the pinnae such as preauricular skin tags and/or ear pits are associated (significantly associated in two of three studies) with a higher prevalence of hearing impairment in most studies [47-49]. In addition, cleft palate is associated with an increased prevalence of conductive hearing loss in children even after surgical repair $[50,51]$.

\section{Recommendations}

The panel of experts recommends performing audiological assessment during the neonatal period in cases with (a) a family history of congenital or early-onset hereditary hearing loss (in parents, grandparents, siblings, or cousins); (b) consanguinity of first or second degree (i.e., parents or grandparents are cousins); and (c) malformations and syndromes associated with hearing loss.

The panel of experts suggests audiological assessment during the neonatal period in the presence of isolated malformations of the pinnae.

\section{Maternal intoxication during pregnancy}

Maternal alcohol consumption in pregnancy, without foetal alcohol syndrome, is not a risk factor for hearing loss. Nevertheless, the prevalence of sensorineural and conductive hearing loss is higher among children who 
suffered from foetal alcohol syndrome than in the general paediatric population [52-54]; the rates of hearing defects were similar to those of newborns with craniofacial anomalies [55-57]. However, other maternal drug abuse during pregnancy, such as cocaine, heroin, and methadone, is not significantly associated with neonatal hearing impairment; studies either failed to show evidence of a significant association or the effects of these drugs on auditory function were inconsistent among studies [57-61].

\section{Recommendations}

The panel of experts recommends performing audiological assessment during the neonatal period in the presence of foetal alcohol syndrome.

The panel of experts recommends performing a hearing screening test in neonates born to mothers who abused drugs during pregnancy.

\section{Specific neonatal conditions: prematurity or low birth weight, Apgar scores, and hyperbilirubinaemia}

Studies analysing low birth weight used different classifications of birth weight, such as low, very low, or extremely low birth weight. Most studies do not provide evidence of a direct association between the neonatal hearing loss and low birth weight, although the prevalence of sensorineural hearing loss is higher in lowbirth-weight neonates [62-66]. This can be explained by the factors commonly related to low birth weight that may have impacted hearing, such as assisted ventilation, ototoxic drug administration, or hyperbilirubinaemia $[67,68]$. Most studies failed to account for these confounding variables in multivariable analysis. Therefore, it weakens the strength of the association.

Another specific indicator of neonates is the Apgar score, which is used as an indicator of birth asphyxia. Studies analysing the association between Apgar score with hearing loss were difficult to compare: the timing of the Apgar score (i.e., 1, 5, or 10 min after birth) and cut-off for birth asphyxia (i.e., Apgar score $<3, \leq 6$ or $<6, \leq 7$ or $<7$, etc.) varied considerably. In some studies, the Apgar score was not associated with hearing loss, whereas in others, a low Apgar score was associated with sensorineural hearing loss or abnormal hearing results, particularly when measured $5 \mathrm{~min}$ after birth (i.e., scores $<3$ or $\leq 6$, or $\leq 7)$ [69-73]. Therefore, further studies are required to clarify the duration of asphyxia, permanent characteristics of hearing deficits related to the Apgar score and birth asphyxia, and role of prematurity, which appears to be a confounding factor $[69,74]$.

Hyperbilirubinaemia is frequently encountered in neonates; severe and very severe cases must be treated by phototherapy or exchange transfusion, respectively. Hearing disabilities among infants with a history of hyperbilirubinaemia are more prevalent than in the general paediatric population $[75,76]$. Indeed, the auditory system is sensitive to bilirubin toxicity, which may lead to bilirubin-induced neurologic dysfunction (BIND) syndrome [77-82]. Some factors such as prematurity, sepsis, and hypoxia may exacerbate bilirubin toxicity $[79,80,83,84]$. The most frequent type of auditory damage is auditory neuropathy or dyssynchrony [80-82]. However, some hearing disabilities are transient and improve with a decrease in the bilirubin level $[85,86]$. Among preterm and full-term infants, the total serum bilirubin level does not appear to be a sensitive or specific indicator for assessing the risk of auditory damage [83]. Moreover, auditory impairment may occur at total bilirubin levels considered 'safe' [80, 84]. Several studies mentioned that besides the bilirubin level, the duration of exposure to bilirubin is related to hearing loss $[80,81,83]$. Therefore, risk assessment for auditory impairment in cases of hyperbilirubinaemia should include several biomarkers and auditory tests [80, 82, 84].

Very low birth weight/prematurity, a low Apgar score/ birth asphyxia, and hyperbilirubinaemia have a cumulative effect, increasing the vulnerability of the brain and auditory function $[69,74,76,78,84]$.

\section{Recommendations}

The panel of experts recommends performing audiological assessment during the neonatal period in cases of (a) a very low birth weight $(<1,500$ g); (b) an Apgar score of $0-6$ at $5 \mathrm{~min}$; and (c) early hyperbilirubinaemia (before day 2) requiring treatment or hyperbilirubinaemia at any day of life requiring either intensive phototherapy or exchange transfusion (based on reference curves).

By placing a high value on avoiding unidentified neonatal hearing loss and because it is painless to perform an audiological assessment, the panel of experts considers very low birth weight a risk factor for hearing loss, even with a 'very low' level of evidence. Moreover, in addition to exchange transfusion, the panel considers early hyperbilirubinaemia and intensive phototherapy a stronger risk factor than that in the JCIH Position Statement (2007) [6]. The panel stresses that improved phototherapy techniques and devices lead to less frequent exchange transfusion treatments. Therefore, they recommend considering early hyperbilirubinaemia and intensive phototherapy as neonatal risk factors for hearing loss; they specifically choose not to make a recommendation based on clinical markers. From a broader perspective, the panel decided a strong recommendation for these three conditions because of their cumulative impact on auditory function susceptibility.

\section{Medical care: NICU stay and use of ventilation or ototoxic drugs}

The JCIH Position Statement (2007) [6] considers a NICU stay exceeding 5 days to be risk factor associated 
with permanent congenital, delayed, or progressive hearing loss [6]. The association between NICU stay (i.e., admission or length of stay) and hearing loss is controversial [73, 87-89]. Indeed, this indicator encompasses multiple conditions and treatments and thus may not reflect the complex and variable health situation of neonates hospitalised in the NICU. Moreover, this indicator is insufficiently considered by multivariable statistical models.

Newborns admitted to the NICU can receive ventilation support with endotracheal ventilation or nasal continuous positive airway pressure (CPAP). The prevalence of hearing loss does not differ significantly between mechanical ventilation and CPAP [90, 91]. Multivariable analyses performed exclusively on preterm neonates indicate that assisted ventilation lasting $>5$ days is an independent risk factor for hearing loss and a risk of failed hearing screening tests [74, 90]. However, a study of newborns admitted to the NICU reported no significant association between hearing loss and endotracheal assisted ventilation or CPAP after adjusting for infants' characteristics and specialised medical procedures [73]. Univariate analyses of different studies of newborns admitted to the NICU showed no significant association between hearing loss and assisted ventilation regardless of whether treatment duration was mentioned. Therefore, current evidence indicates that assisted ventilation is not obviously a neonatal risk factor for hearing loss [92, 93].

Ototoxic drugs, specifically aminoglycosides and loop diuretics, can be administered to newborns. However, the association between aminoglycoside administration and hearing loss is inconsistent among studies; most studies reported no significant association with treatment duration, total dose, or peak or trough serum concentrations [94-98], whereas others reported ototoxicity of aminoglycosides [88, 94, 95, 97-100], particularly on highfrequency hearing $[67,99]$. In some individuals, genetic predisposition (i.e., a specific mutation of mitochondrial DNA) is associated with aminoglycoside-induced and non-syndromic sensorineural hearing loss, making them particularly vulnerable to aminoglycoside toxicity [101]. The association between loop diuretics administered to neonates and hearing loss is also inconsistent. However, their (over) use in combination with other treatments (e.g., aminoglycosides) appears to be associated with sensorineural hearing loss $[97,102]$. The transient characteristic of loop diuretic-associated hearing loss has also been discussed [67]. In those studies, the administration of ototoxic drugs was supposed to be clinically appropriate; inappropriate or uncontrolled drug administration may have shown a different association with hearing loss.

Extracorporeal membrane oxygenation (ECMO) is an extreme medical therapy used in critically ill newborns. The incidence of sensorineural hearing loss reported among infants who have received ECMO varies widely among studies, but is higher than that in the general paediatric population $[103,104]$. However, these neonates also received other extreme treatments and medical care that could be related to sensorineural hearing loss. As the hearing impairment reported in ECMO-treated neonates may be late-onset or progressive, follow-up during childhood is recommended among those treated with ECMO [103-105]. Studies about hearing loss frequently investigated congenital diaphragmatic hernia and inhaled nitric oxide in combination with ECMO. The incidence rates of hearing loss associated with congenital diaphragmatic hernia are inconsistent in the literature [106-109]. Moreover, such infants require other treatments and may suffer from other conditions that are associated with or are considered risk factors for sensorineural hearing loss. Furthermore, there is no significant difference in the rate of sensorineural hearing loss between neonates treated with inhaled nitric oxide and those treated with either $100 \%$ oxygen or simulated initiation treatment $[110,111]$. The high prevalence of sensorineural hearing loss in neonates treated with inhaled nitric oxide may be due to other conditions or therapies. Hence, the relationship between hearing loss and specific conditions and treatments in critically ill neonates, such as ECMO, congenital diaphragmatic hernia, and inhaled nitric oxide, require further investigation despite the small numbers of cases.

\section{Recommendations}

The panel of experts recommends performing audiological assessment during the neonatal period after ECMO treatment.

The panel of experts suggests performing audiological assessment during the neonatal period in cases of (a) a NICU stay exceeding 5 days; (b) assisted ventilation lasting at least $24 \mathrm{~h}$; and (c) ototoxic drug (i.e., aminoglycosides or loop diuretics) administration regardless of treatment length.

The panel of experts' recommendations regarding NICU stay and ototoxic drugs are concordant with those of the JCIH Position Statement (2007) [6]. They consider assisted ventilation to include mechanical ventilation (with endotracheal intubation) and CPAP. The 24-h duration of assisted ventilation was included as a criterion of ill newborns. The panel proposed no specific recommendations regarding neonates suffering from congenital diaphragmatic hernia or those treated with inhaled nitric oxide; because of their medical condition, they will be ventilated and thus should have an audiological assessment as suggested.

\section{Specific diseases: neurologic or endocrine diseases}

Neurologic diseases in neonates include meningitis and intraventricular haemorrhage. The risk of hearing loss 
due to meningitis varies widely in the literature, although the reported rates are higher than those in the general population; the long-term consequences such as improvement/worsening of impairment also vary [112114]. Neonates with intraventricular haemorrhage, which is specific to preterm infants, exhibit a slightly higher prevalence of hearing loss, but an in-depth study highlights the role of white matter lesions over the intraventricular haemorrhage on neurodevelopmental outcomes such hearing loss [115-117].

Congenital hypothyroidism is strongly associated with a higher prevalence of hearing loss than that in the general population; reported cases of hearing loss are mostly bilateral and of mild to moderate severity [118-120]. Phenylketonuria is a congenital endocrine disease that is universally screened and treated; therefore, an association between this disease, specifically if untreated, and hearing loss is difficult to determine; the associations of other endocrine diseases such the thrifty phenotype hypothesis with hearing loss also require further investigation [121, 122].

\section{Recommendations}

The panel of experts recommends performing audiological assessment during the neonatal period in neonates (a) who have suffered from meningitis or require a neurologic consultation (i.e., convulsion, hypotonia, swallowing/ feeding difficulties, and cranial nerve palsy) and (b) with congenital hypothyroidism.

Meningitis is confirmed by positive culture. The panel of experts highlights some specific neurologic conditions for paediatricians and otorhinolaryngologists, even without rigorous evidence of an association with hearing loss. This recommendation is based on the experts' clinical experience.

The panel of experts suggests performing audiological assessment during the neonatal period in neonates with white matter lesions or intraventricular haemorrhage.

\section{Specific elements emerging from the consensus Cumulative effect of risk factors on hearing function}

The panel of experts explicitly highlights situations in which newborns exhibit more than one risk factor for hearing loss; the prevalence and severity of hearing loss increase with an increasing number of risk factors [123]. Therefore, such newborns require special attention.

\section{Reassessment of risk factors}

The panel insists these neonatal risk factors for hearing loss are applicable during the first month of life and should be reassessed in cases showing changes in health condition during that period (e.g., in case of readmission).

\section{Recommended hearing tests and timing of the tests (initial assessment and follow-up) \\ Timing of the initial audiological assessment}

When an audiological assessment is suggested or recommended, the panel of experts highlights the necessity to perform (to the extent possible) hearing tests before hospital discharge. In cases involving admission to the NICU in particular, neonate hospitalisation is stressful for the parents; therefore, they should not be required to return to the hospital after discharge, if possible. The goal is to avoid losses to follow-up and thus undiagnosed cases. If audiological assessment is not performed before discharge because of a short hospital stay, an outpatient appointment should be made during the following month at the latest. The appointment should be scheduled before discharge.

\section{Hearing tests for the initial audiological assessment}

The panel of experts states that the audiological assessment should at least include an auditory brainstem response to assess the entire auditory brainstem pathway. The tests should be chosen within the competency of the otorhinolaryngologist in charge of the patient and in accordance with the context and situation.

\section{Follow-up}

The panel of experts recommends audiological followup for all children who have undergone audiological assessment at birth; this follow-up should be performed once between the ninth and twelfth months of life. The panel of experts identifies two exceptions. First, children with congenital CMV infection, a family history of congenital or early-onset hereditary hearing loss, a family history of consanguinity of the first or second degree, malformations and syndromes associated with hearing loss, or those treated with ECMO should undergo audiological follow-up every 4-6 months during their first two years of life. Their hearing should be reassessed annually between 2 and 6 years of age. Second, neonates treated with ototoxic drugs should undergo audiological follow-up once during the first 3 months of life. The otorhinolaryngologist will judge the appropriate hearing tests to perform during follow-up, depending on the child's risk factors and age.

\section{Discussion}

This study aimed to update the recommendations for the clinical management and follow-up of children with neonatal risk factors for hearing loss in the newborn hearing screening programme in the FWB in Belgium. To this end, we used methodological tools, including the formulation of PICO questions, a literature review to establish the state of scientific knowledge on risk factors for hearing loss, the GRADE system assessment, and a 
consensus process with a panel of experts. The findings of this study will ultimately improve clinical practice through the earlier identification of newborns suffering from hearing loss and adequate follow-up of children at risk of delayed or late-onset hearing loss. Indeed, the newborn hearing screening programme in Belgium is based on the presence or absence of risk factor(s) for hearing loss. Therefore, an accurate, sensitive, and wellformulated list of neonatal risk factors for hearing loss and recommendations for their management is essential. However, the misidentification of risk factors for hearing loss may lead to unnecessary assessment and stress for parents; alternatively, newborns with neonatal hearing loss may be overlooked because of having been subjected to an insufficiently accurate audiological test. Modification of the protocol design of the hearing screening programme was unfeasible because it would have required the analysis of complex technical questions such as available automated hearing tests and their classification algorithms of normal versus unsatisfactory results, organisational matters, cost-effectiveness, and the global system of newborn hearing screening in Belgium.

The state of knowledge about the neonatal risk factors for hearing loss highlights the effects of treatment; in the cases of some infectious risk factors such as congenital CMV, toxoplasmosis, and syphilis infections, treatments have modified the risk of developing hearing loss or prevented hearing deterioration. When such diseases are treated early after birth, congenitally infected children have a lower risk of developing hearing loss than those without treatment $[20,25,29]$. Therefore, the early identification of these risk factors is essential during prenatal care or at birth at the latest to initiate treatment. The rubella vaccination already changed the situation; because of the vaccine and widespread immunization, congenital rubella and hearing loss due to the disease have become extremely rare in Belgium [27]. However, congenital rubella must still be considered a risk factor in the hearing screening programme, particularly for neonates born to unvaccinated mothers. Likewise, the treatment of hyperbilirubinaemia reduces the risk of auditory damage. Treatment reduces the risk of developing hearing loss in some cases, whereas treatments such as ototoxic drugs, ECMO, or ventilation are actually risk factors. Although the development and evolution of these techniques or treatments has led to better control, they must still be used carefully and newborns should be monitored closely. Because of these advances in healthcare, analysing risk factors for hearing loss on the basis of studies performed decades ago is not recommended. Therefore, to avoid inaccurate information, we limited our literature review as much as possible to articles published during the last 15 years. We also rated the quality of evidence without including the treatment effect to ensure a standardised perspective.

Drawing conclusions from published studies was sometimes made difficult by the studies themselves. In particular, multivariable analyses were not performed systematically, and the numbers of children with hearing impairment identified in the studies were limited. Firstly, ill newborns frequently exhibit multiple risk factors such as prematurity, NICU stay, ototoxic drug administration, ventilation, etc. Hence, it is essential to consider the actual impact of individual risk factors on hearing function. Therefore, univariate analyses were insufficient, and multivariable models were not performed systematically. Second, the few cases of children with hearing impairment also complicated the drawing of conclusions; the low prevalence (a small percentage) of hearing loss applied to small samples (usually $<500$ newborns) led to the identification of only a few hearing-impaired newborns. Random sampling may have dramatically affected the numbers of identified children with hearing impairment results and thus statistical power. Furthermore, there were multiple definitions of hearing loss and a wide range of hearing tests and clinical criteria as well as failure to consider other risk factors and inconsistent results among studies in some cases.

To avoid bias in the literature review and determine the states of scientific knowledge, we developed a thorough and exhaustive approach. Although we investigated the risk factors for hearing loss individually, when pertinent, we presented their cumulative effects on hearing function by using a transversal approach. By making specific inquiries during the literature review, we detected risk factors for hearing loss that would not have been included in the original list. Because of this exhaustive approach, we decided to add three risk factors to our investigation: ECMO, congenital diaphragmatic hernia, and inhaled nitric oxide. We strictly limited our research to medical conditions and factors, although sociodemographic factors have been reported as other potential risk factors for neonatal hearing loss [124]. Although the association of sociodemographic factors with hearing loss is poorly understood, they appear to be part of a more complex relationship; that is, sociodemographic factors appeared to be related to medical conditions or risk factors already associated with hearing loss. These kinds of risk factors were not included in the newborn hearing screening programme but should be monitored in the FWB to clarify their associations.

It is important to note that the studies retrieved through the literature review were mostly observational and thus started at a 'low' level of evidence quality. Nonetheless, the GRADE system is flexible, as the quality of evidence can be rated on the basis of methodological criteria [125]. Indeed, we uprated the quality of 
evidence for some risk factors even though the studies were exclusively observational [11]. However, rating the quality of evidence involves making a judgment to choose the best classification, whereas quality generally appears to be distributed in a continuum; this arbitrariness implies subjectivity. The transparency of the process and the detailed summary of findings and arguments that arose when rating the levels of evidence helped reduce this subjectivity. With the aim of transparency, we mentioned the arguments for the levels of evidence quality (Additional file 1: Table S1).

The GRADE system is usually used in the clinical management of therapies but can also be used in all healthcare management decision making $[13,126]$. Our research objective did not focus on therapy or diagnostic tests [127]. However, the Belgian Health Care Knowledge Centre used the GRADE system to identify risk factors for a breast screening programme [128]. This bolsters our confidence in the application of the GRADE system in the present study. Nonetheless, the panel of experts was not always comfortable with the application of the GRADE system. They were all clinicians, and the conflict between the evidence-based (i.e., epidemiological) approach and their clinical experience (i.e., individual approach) was challenging. Rating the quality of evidence needed to be discussed specifically during the face-to-face meeting; in particular, it was pointed out that a low quality of evidence does not necessarily mean that the element should not be considered a risk factor for hearing loss but that the rating also results from the type of study, biases, limitations, results, and methodology.

Beyond the quality of evidence, the recommendation formulation considers other parameters such as benefit/ harm balance, resource use, and patients' values and preferences [14]. The panel of experts aided the transition from quality of evidence to recommendations owing to their medical expertise and knowledge about the subject and clinical practice. Indeed, in our context, the inadequate identification of risk factors for hearing loss affected the balance between misdiagnosis (or delayed diagnosis), parental stress, and good allocation of human, technical, and financial resources (for the family and society). In the absence of known risk factors for hearing loss, a mass screening test is performed by professionals with basic training (i.e., professionals not specialised in audiology); this requires less time and a less expensive device, incurring less parental stress than an audiological assessment. However, the automated otoacoustic emissions hearing screening technique implemented in the screening programme is not sufficiently sensitive in the presence of risk factor(s) and may not identify neonatal hearing loss. Indeed, retrocochlear hearing loss is more frequently encountered in the presence of a risk factor and may not be detected by an otoacoustic emissions test (cochlear testing). Therefore, an up-to-date list of risk factors and recommendations is important to ensure the quality of the newborn hearing screening programme and the health system sector responsible for hearing problems. In cases in which it was unclear whether to include a risk factor in the updated list, the panel of experts gave more weight to the fact that audiological assessment is not painful and prevents delayed diagnosis, even though this technique requires more time for both the family and healthcare professionals and can incur parental stress; in such cases, they developed a conservative approach and always considered unclear factors as risk factors for hearing loss. In other words, the expert panel emphasises avoiding delayed diagnosis or misdiagnosis, even if incurring unnecessary hearing tests. According to the GRADE system, the 'patient important outcome' must be included in the recommendations [14]. Patients' values and preferences must also be included in the grading [14]. However, during the entire research process, more precisely in the development of recommendations, patients' or their parents'/guardians' perspectives were not consulted; their input was only indirectly included according to the clinical experiences of the panel of experts.

To foster rapid and complete acceptance, the recommendations were written to be helpful and clear. The next step after the publication of these updated recommendations is to implement the updated list of risk factors for hearing loss in the programme. The challenge is to convince paediatricians and otorhinolaryngologists to implement this updated list and follow the recommendations by adapting their clinical practice. Having pertinent and adequate recommendations but not using them would negatively impact the newborn hearing screening programme. Therefore, the dissemination of the updated list, recommendations, and underlying scientific arguments is strongly advised. They can be presented at national paediatric or otorhinolaryngology congresses and directly to local hospital staff.

\section{Conclusions}

We updated the risk factors for hearing loss for the newborn hearing screening programme in Belgium (FWB) by combining an evidence-based approach and the clinical experience of a panel of experts. Hence, we developed recommendations for the clinical management and follow-up of newborns with neonatal risk factors for hearing loss. As the recommended hearing tests and follow-up regime differ depending on the presence or absence of these risk factors in newborns, it is essential to correctly identify newborns with neonatal risk factor(s) for hearing loss. The quality of evidence for the risk factors for hearing loss ranged from 'very low', due to the absence of scientific evidence or methodological 
weaknesses in studies, to 'high', mostly when the physiopathology of the risk factor on the auditory function is understood. The recommendations were also graded as 'weak' or 'strong'. Moreover, the panel of experts emphasises avoiding unidentified neonatal hearing loss and recommends considering unclear factors as risk factors for hearing loss. The next step is to implement these recommendations, which will improve the ability of the hearing screening programme to identify hearing loss in children and perform adequate follow-up of children at risk of later onset; regular monitoring of the screening programme should integrate this updated list of risk factors.

\section{Additional file}

Additional file 1: Table S1. Rating of the quality of evidence for the risk factors for hearing loss. (PDF $51 \mathrm{~kb}$ )

\section{Abbreviations}

BIND: Bilirubin-induced neurologic dysfunction; CMV: Cytomegalovirus; CPAP: Continuous positive airway pressure; ECMO: Extracorporeal membrane oxygenation; FWB: Fédération Wallonie-Bruxelles; GRADE: Grading of Recommendations, Assessment, Development and Evaluation; JCIH: Joint Committee on Infant Hearing; MeSH: Medical Subject Headings; NICU: Neonatal intensive care unit; PICO: Population, intervention, comparison, and outcomes.

\section{Competing interests}

The authors declare that they have no competing interests.

\section{Authors' contributions}

BV participated in the design of the study, performed the literature review, managed the consensus process, and drafted the manuscript. CS participated in the design of the consensus process, partook in the redaction of the manuscript, and critically reviewed the text. $R L$ and $A L$ participated in the design of the study, partook in the redaction of the manuscript, and critically reviewed the text. Members of the Surdiscreen group participated in the redaction of the Results section, partook in the consensus process, and critically reviewed the manuscript. All authors read and approved the final manuscript.

\section{Acknowledgements}

The SurdiScreen Group consists of Dr. Isabelle Courtmans (Centre Comprendre et Parler, Brussels), Professor Paul Deltenre (CHU Brugmann, Brussels), Professor Naima Deggouj (Cliniques Universitaires St Luc, Brussels), Dr. Laurent Demanez (CHU de Liège, Liège), Dr. Anne Doyen (CHWAPI, Tournai; Cliniques Universitaires St Luc, Brussels), Dr. Pascale Eymael (CHR de la Citadelle, Liège), Dr. Liliane Gilbert (Office de la Naissance et de l'Enfance, Brussels), Dr. Chantal Ligny (Centre de Comprendre et Parler, Brussels), Professor Anne-Laure Mansbach (Hôpital Universitaire des Enfants Reine Fabiola, Brussels), Dr. Nathalie Mélice (Office de la Naissance et de l'Enfance, Brussels), Dr. Catherine Pieltain (CHU-CHR de Liège, Liège), Dr. Patricia Simon (Hôpital Civil Marie Curie, Charleroi; Centre Comprendre et Parler, Brussels), and Dr. Alexandra Urth (CHU Notre Dame des Bruyères, Liège).

The authors would like to thank Editage (www.editage.com) for the English language editing.

The Fédération Wallonie-Bruxelles funded the newborn hearing screening programme and had no other involvement in this article.

\section{Author details}

${ }^{1}$ Research Center Epidemiology, Biostatistics and Clinical Research, Université libre de Bruxelles (ULB), School of Public Health, Route de Lennik 808, Brussels 1070, Belgium. ${ }^{2}$ Research Center Health Policy and Systems International Health, Université libre de Bruxelles (ULB), School of Public Health, Route de Lennik 808, Brussels 1070, Belgium. ${ }^{3}$ Centre d'Epidémiologie Périnatale (CEpiP), Route de Lennik 808, Brussels 1070, Belgium.
Received: 11 May 2015 Accepted: 8 October 2015

Published online: 16 October 2015

\section{References}

1. Erenberg A, Lemons J, Sia C, Trunkel D, Ziring P. Newborn and infant hearing loss: detection and intervention. American Academy of Pediatrics. Task Force on Newborn and Infant Hearing, 1998-1999. Pediatrics. 1999;103:527-30

2. Yoshinaga-Itano C. From screening to early identification and intervention: discovering predictors to successful outcomes for children with significant hearing loss. J Deaf Stud Deaf Educ. 2003:8:11-30.

3. Meinzen-Derr J, Wiley S, Choo DI. Impact of early intervention on expressive and receptive language development among young children with permanent hearing loss. Am Ann Deaf. 2011;155:580-91.

4. Vohr B, Jodoin-Krauzyk J, Tucker R, Topol D, Johnson MJ, Ahlgren M, et al. Expressive vocabulary of children with hearing loss in the first 2 years of life: impact of early intervention. J Perinatol. 2011;31:274-80.

5. European Consensus Statement on Neonatal Hearing Screening. Finalized at the European Consensus Development Conference on Neonatal Hearing Screening. Milan, 15-16 May 1998. Acta Paediatr. 1999, 88:107-108

6. Joint Committee on Infant Hearing. Year 2007 position statement: Principles and guidelines for early hearing detection and intervention programs. Pediatrics. 2007;120:898-921.

7. US Preventive Services Task Force. Universal screening for hearing loss in newborns: US Preventive Services Task Force recommendation statement. Pediatrics. 2008;122:143-8.

8. Beswick R, Driscoll C, Kei J. Monitoring for postnatal hearing loss using risk factors: a systematic literature review. Ear Hear. 2012;33:745-56.

9. Wood SA, Davis AC, Sutton GJ. Effectiveness of targeted surveillance to identify moderate to profound permanent childhood hearing impairment in babies with risk factors who pass newborn screening. Int J Audiol. 2013;52:394-9.

10. Joint Committee on Infant Hearing, American Academy of Audiology, American Academy of Pediatrics, American Speech-Language-Hearing Association, and Directors of Speech and Hearing Programs in State Health and Welfare Agencies. Year 2000 position statement: principles and guidelines for early hearing detection and intervention programs. Pediatrics. 2000;106:798-817.

11. Guyatt GH, Oxman AD, Kunz R, Vist GE, Falck-Ytter Y, Schünemann HJ. GRADE: What is "quality of evidence" and why is it important to clinicians? BMJ. 2008:336:995-8.

12. Atkins $D$, Best $D$, Briss PA, Eccles M, Falck-Ytter $Y$, Flottorp $S$, et al. Grading quality of evidence and strength of recommendations. BMJ. 2004;328:1490.

13. Guyatt GH, Oxman AD, Vist GE, Kunz R, Falck-Ytter $Y$, Alonso-Coello P, et al. GRADE: an emerging consensus on rating quality of evidence and strength of recommendations. BMJ. 2008;336:924-6.

14. Guyatt GH, Oxman AD, Kunz R, Falck-Ytter $Y$, Vist GE, Liberati A, et al. GRADE: Going from evidence to recommendations. BMJ. 2008;336:1049-51.

15. Arnold GL, Van Hove J, Freedenberg D, Strauss A, Longo N, Burton B, et al. A Delphi clinical practice protocol for the management of very long chain acyl-CoA dehydrogenase deficiency. Mol Genet Metab. 2009;96:85-90.

16. Foulon I, Naessens A, Foulon W, Casteels A, Gordts F. A 10-year prospective study of sensorineural hearing loss in children with congenital cytomegalovirus infection. J Pediatr. 2008;153:84-8.

17. Goderis J, De Leenheer E, Smets K, Van Hoecke H, Keymeulen A, Dhooge I. Hearing loss and congenital CMV infection: a systematic review. Pediatrics. 2014;134:972-82.

18. Kadambari S, Williams EJ, Luck S, Griffiths PD, Sharland M. Evidence based management guidelines for the detection and treatment of congenital CMV. Early Hum Dev. 2011;87:723-8.

19. Kimberlin DW, Acosta EP, Sánchez PJ, Sood S, Agrawal V, Homans J, et al. Pharmacokinetic and pharmacodynamic assessment of oral valganciclovir in the treatment of symptomatic congenital cytomegalovirus disease. J Infect Dis. 2008;197:836-45.

20. Kimberlin DW, Lin CY, Sánchez PJ, Demmler GJ, Dankner W, Shelton M, et al. Effect of ganciclovir therapy on hearing in symptomatic congenital cytomegalovirus disease involving the central nervous system: a randomized, controlled trial. J Pediatr. 2003;143:16-25.

21. Oliver SE, Cloud GA, Sanchez PJ, Demmler GJ, Dankner W, Shelton M, et al. Neurodevelopmental outcomes following ganciclovir therapy in symptomatic congenital cytomegalovirus infections involving the central nervous system. J Clin Virol. 2009;46 Suppl 4:S22-26. 
22. Andrade GM, Resende LM, Goulart EM, Siqueira AL, Vitor RW, Januario JN. Hearing loss in congenital toxoplasmosis detected by newborn screening. Braz J Otorhinolaryngol. 2008;74:21-8.

23. Banatvala JE, Brown DW. Rubella. Lancet. 2004;363:1127-37.

24. Best JM. Rubella. Semin Fetal Neonatal Med. 2007;12:182-92.

25. Brown ED, Chau JK, Atashband S, Westerberg BD, Kozak FK. A systematic review of neonatal toxoplasmosis exposure and sensorineural hearing loss. Int J Pediatr Otorhinolaryngol. 2009:73:707-11.

26. McGee T, Wolters C, Stein L, Kraus N, Johnson D, Boyer K, et al. Absence of sensorineural hearing loss in treated infants and children with congenital toxoplasmosis. Otolaryngol Head Neck Surg. 1992;106:75-80.

27. Simons EA, Reef SE, Cooper LZ, Zimmerman L, Thompson KM. Systematic Review of the Manifestations of Congenital Rubella Syndrome in Infants and Characterization of Disability-Adjusted Life Years (DALYs). Risk Anal. 2014. doi:10.1111/risa.12263

28. Austeng ME, Eskild A, Jacobsen M, Jenum PA, Whitelaw A, Engdahl B. Maternal infection with toxoplasma gondii in pregnancy and the risk of hearing loss in the offspring. Int J Audiol. 2010;49:65-8.

29. Chau J, Atashband S, Chang E, Westerberg BD, Kozak FK. A systematic review of pediatric sensorineural hearing loss in congenital syphilis. Int J Pediatr Otorhinolaryngol. 2009;73:787-92.

30. Gleich LL, Urbina M, Pincus RL. Asymptomatic congenital syphilis and auditory brainstem response. Int J Pediatr Otorhinolaryngol. 1994;30:11-3.

31. McLeod R, Boyer K, Karrison T, Kasza K, Swisher C, Roizen N, et al. Outcome of treatment for congenital toxoplasmosis, 1981-2004: the national collaborative Chicago-based, congenital toxoplasmosis study. Clin Infect Dis. 2006:42:1383-94

32. Niedzielska G, Katska E, Szymula D. Hearing defects in children born of mothers suffering from rubella in the first trimester of pregnancy. Int J Pediatr Otorhinolaryngol. 2000;54:1-5.

33. Westerberg BD, Atashband S, Kozak FK. A systematic review of the incidence of sensorineural hearing loss in neonates exposed to Herpes simplex virus (HSV). Int J Pediatr Otorhinolaryngol. 2008;72:931-7.

34. Bener A, Eihakeem AA, Abdulhadi K. Is there any association between consanguinity and hearing loss. Int J Pediatr Otorhinolaryngol. 2005;69:327-33.

35. Feinmesser $\mathrm{M}$, Tell $\mathrm{L}$, Levi $\mathrm{H}$. Consanguinity among parents of hearingimpaired children in relation to ethnic groups in the Jewish population of Jerusalem. Audiology. 1989;28:268-71.

36. Zakzouk SM, Bafaqeeh SA. Prevalence of severe to profound sensorineural hearing loss in children having family members with hearing impairment. Ann Otol Rhinol Laryngol. 1996;105:882-6.

37. Grundfast KM, Siparsky N, Chuong D. Genetics and molecular biology of deafness. Update. Otolaryngol Clin North Am. 2000;33:1367-94.

38. Pickett BP, Ahlstrom K. Clinical evaluation of the hearing-impaired infant. Otolaryngol Clin North Am. 1999;32:1019-35.

39. Tekin M, Arnos KS, Pandya A. Advances in hereditary deafness. Lancet. 2001;358:1082-90

40. Driscoll C, Beswick R, Doherty E, D'Silva R, Cross A. The validity of family history as a risk factor in pediatric hearing loss. Int J Pediatr Otorhinolaryngol. 2015.

41. Khabori MA, Patton MA. Consanguinity and deafness in Omani children. Int J Audiol. 2008;47:30-3.

42. Levi H, Tell L, Cohen T. Sensorineural hearing loss in Jewish children born in Jerusalem. Int J Pediatr Otorhinolaryngol. 2004;68:1245-50.

43. Zakzouk S. Consanguinity and hearing impairment in developing countries: a custom to be discouraged. J Laryngol Otol. 2002;116:811-6.

44. Dror AA, Avraham KB. Hearing loss: mechanisms revealed by genetics and cell biology. Annu Rev Genet. 2009;43:411-37.

45. Morton CC, Nance WE. Newborn hearing screening-a silent revolution. N Engl J Med. 2006;354:2151-64.

46. Nance WE. The genetics of deafness. Ment Retard Dev Disabil Res Rev. 2003:9:109-19.

47. Firat Y, Sireci S, Yakinci C, Akarcay M, Karakas HM, Firat AK, et al. Isolated preauricular pits and tags: is it necessary to investigate renal abnormalities and hearing impairment? Eur Arch Otorhinolaryngol. 2008;265:1057-60.

48. Kugelman A, Hadad B, Ben-David J, Podoshin L, Borochowitz Z, Bader D. Preauricular tags and pits in the newborn: the role of hearing tests. Acta Paediatr. 1997:86:170-2.

49. Roth DA, Hildesheimer M, Bardenstein S, Goidel D, Reichman B, MaayanMetzger A, et al. Preauricular skin tags and ear pits are associated with permanent hearing impairment in newborns. Pediatrics. 2008;122:e884-890.
50. Carroll DJ, Padgitt NR, Liu M, Lander TA, Tibesar RJ, Sidman JD. The effect of cleft palate repair technique on hearing outcomes in children. Int J Pediatr Otorhinolaryngol. 2013;77:1518-22.

51. Paliobei V, Psifidis A, Anagnostopoulos D. Hearing and speech assessment of cleft palate patients after palatal closure. Long-term results. Int J Pediatr Otorhinolaryngol. 2005;69:1373-81.

52. Church MW, Eldis F, Blakley BW, Bawle EV. Hearing, language, speech, vestibular, and dentofacial disorders in fetal alcohol syndrome. Alcohol Clin Exp Res. 1997;21:227-37.

53. Cone-Wesson B. Prenatal alcohol and cocaine exposure: influences on cognition, speech, language, and hearing. J Commun Disord. 2005;38:279-302.

54. Rössig C, Wässer S, Oppermann P. Audiologic manifestations in fetal alcohol syndrome assessed by brainstem auditory-evoked potentials. Neuropediatrics. 1994:25:245-9.

55. Church MW, Abel EL. Fetal alcohol syndrome. Hearing, speech, language, and vestibular disorders. Obstet Gynecol Clin North Am. 1998;25:85-97.

56. Church MW, Kaltenbach JA. Hearing, speech, language, and vestibular disorders in the fetal alcohol syndrome: a literature review. Alcohol Clin Exp Res. 1997;21:495-512.

57. Gerber SE, Epstein L, Mencher LS. Recent changes in the etiology of hearing disorders: perinatal drug exposure. J Am Acad Audiol. 1995:6:371-7.

58. Carzoli RP, Murphy SP, Hammer-Knisely J, Houy J. Evaluation of auditory brain-stem response in full-term infants of cocaine-abusing mothers. Am J Dis Child. 1991;145:1013-6.

59. Grimmer I, Bührer C, Aust G, Obladen M. Hearing in newborn infants of opiate-addicted mothers. Eur J Pediatr. 1999;158:653-7.

60. Shih L, Cone-Wesson B, Reddix B. Effects of maternal cocaine abuse on the neonatal auditory system. Int J Pediatr Otorhinolaryngol. 1988;15:245-51.

61. Tan-Laxa MA, Sison-Switala C, Rintelman W, Ostrea Jr EM. Abnormal auditory brainstem response among infants with prenatal cocaine exposure. Pediatrics. 2004;113:357-60.

62. Ari-Even Roth D, Hildesheimer M, Maayan-Metzger A, Muchnik C, Hamburger A, Mazkeret R, et al. Low prevalence of hearing impairment among very low birthweight infants as detected by universal neonatal hearing screening. Arch Dis Child Fetal Neonatal Ed. 2006;91:F257-262.

63. Borkoski-Barreiro SA, Falcon-González JC, Liminana-Canal JM, Ramos-Macias A. Evaluation of very low birth weight $(\leq 1,500 \mathrm{~g})$ as a risk indicator for sensorineural hearing loss. Acta Otorrinolaringol Esp. 2013;64:403-8.

64. Doyle LW, Keir E, Kitchen WH, Ford GW, Rickards AL, Kelly EA. Audiologic assessment of extremely low birth weight infants: a preliminary report. Pediatrics. 1992;90:744-9.

65. Martinez-Cruz CF, Garcia Alonso-Themann P, Poblano A, Ochoa-Lopez JM. Hearing loss, auditory neuropathy, and neurological co-morbidity in children with birthweight <750 g. Arch Med Res. 2012;43:457-63.

66. Van Naarden K, Decoufle P. Relative and attributable risks for moderate to profound bilateral sensorineural hearing impairment associated with lower birth weight in children 3 to 10 years old. Pediatrics. 1999;104:905-10.

67. Cristobal R, Oghalai JS. Hearing loss in children with very low birth weight: current review of epidemiology and pathophysiology. Arch Dis Child Fetal Neonatal Ed. 2008;93:F462-468.

68. Soleimani F, Zaheri F, Abdi F. Long-term neurodevelopmental outcomes after preterm birth. Iran Red Crescent Med J. 2014;16:e17965.

69. Borg E. Perinatal asphyxia, hypoxia, ischemia and hearing loss. An overview. Scand Audiol. 1997;26:77-91.

70. Jiang ZD, Wilkinson AR. Neonatal auditory function and depressed Apgar score: correlation of brainstem auditory response with Apgar score. Acta Paediatr. 2006:95:1556-60.

71. Jiang ZD, Wilkinson AR. Relationship between brainstem auditory function during the neonatal period and depressed Apgar score. J Matern Fetal Neonatal Med. 2010;23:973-9.

72. Kvestad E, Lie KK, Eskild A, Engdahl B. Sensorineural hearing loss in children: the association with Apgar score. A registry-based study of 392,371 children in Norway. Int J Pediatr Otorhinolaryngol. 2014;78:1940-4.

73. van Dommelen $\mathrm{P}$, Mohangoo AD, Verkerk PH, van der Ploeg $C P$, van Straaten HL. Risk indicators for hearing loss in infants treated in different neonatal intensive care units. Acta Paediatr. 2010:99:344-9.

74. Hille ET, van Straaten HI, Verkerk PH. Prevalence and independent risk factors for hearing loss in NICU infants. Acta Paediatr. 2007;96:1155-8.

75. Akinpelu OV, Waissbluth S, Daniel SJ. Auditory risk of hyperbilirubinemia in term newborns: a systematic review. Int J Pediatr Otorhinolaryngol. 2013;77:898-905 
76. Hulzebos CV, van Dommelen P, Verkerk PH, Dijk PH, Van Straaten HL. Evaluation of treatment thresholds for unconjugated hyperbilirubinemia in preterm infants: effects on serum bilirubin and on hearing loss? PLOS One. 2013:8:e62858.

77. Bhutani VK, Wong R. Bilirubin-induced neurologic dysfunction (BIND). Semin Fetal Neonatal Med. 2015;20:1.

78. Johnson L, Bhutani VK. The clinical syndrome of bilirubin-induced neurologic dysfunction. Semin Perinatol. 2011;35:101-13.

79. Morioka I, Iwatani S, Koda T, lijima K, Nakamura H. Disorders of bilirubin binding to albumin and bilirubin-induced neurologic dysfunction. Semin Fetal Neonatal Med. 2014.

80. Olds C, Oghalai JS. Audiologic impairment associated with bilirubin-induced neurologic damage. Semin Fetal Neonatal Med. 2015;20:42-6.

81. Shapiro SM, Nakamura H. Bilirubin and the auditory system. J Perinatol. 2001;21 Suppl 1:S52-55. discussion S59-62.

82. Shapiro SM, Popelka GR. Auditory impairment in infants at risk for bilirubininduced neurologic dysfunction. Semin Perinatol. 2011;35:162-70.

83. Bhutani VK, Johnson-Hamerman L. The clinical syndrome of bilirubin-induced neurologic dysfunction. Semin Fetal Neonatal Med. 2015;20:6-13.

84. Shapiro SM. Bilirubin toxicity in the developing nervous system. Pediatr Neurol. 2003;29:410-21.

85. Tan KL, Skurr BA, Yip YY. Phototherapy and the brain-stem auditory evoked response in neonatal hyperbilirubinemia. J Pediatr. 1992;120:306-8.

86. Wong V, Chen WX, Wong KY. Short- and long-term outcome of severe neonatal nonhemolytic hyperbilirubinemia. J Child Neurol. 2006;21:309-15.

87. Coenraad S, Goedegebure A, van Goudoever JB, Hoeve LJ. Risk factors for sensorineural hearing loss in NICU infants compared to normal hearing NICU controls. Int J Pediatr Otorhinolaryngol. 2010;74:999-1002.

88. Kraft CT, Malhotra S, Boerst A, Thorne MC. Risk indicators for congenital and delayed-onset hearing loss. Otol Neurotol. 2014;35:1839-43.

89. Xoinis K, Weirather Y, Mavoori H, Shaha SH, Iwamoto LM. Extremely low birth weight infants are at high risk for auditory neuropathy. J Perinatol. 2007;27:718-23.

90. Rastogi S, Mikhael M, Filipov P, Rastogi D. Effects of ventilation on hearing loss in preterm neonates: Nasal continuous positive pressure does not increase the risk of hearing loss in ventilated neonates. Int J Pediatr Otorhinolaryngol. 2013;77:402-6.

91. Thomas CW, Meinzen-Derr J, Hoath SB, Narendran V. Neurodevelopmental outcomes of extremely low birth weight infants ventilated with continuous positive airway pressure vs. mechanical ventilation. Indian J Pediatr. 2012;79:218-23.

92. Pourarian S, Khademi B, Pishva N, Jamali A. Prevalence of hearing loss in newborns admitted to neonatal intensive care unit. Iran J Otorhinolaryngol. 2012;24:129-34

93. Speleman K, Kneepkens K, Vandendriessche K, Debruyne F, Desloovere C. Prevalence of risk factors for sensorineural hearing loss in NICU newborns. B-ENT. 2012:8:1-6.

94. de Hoog M, van Zanten BA, Hop WC, Overbosch E, Weisglas-Kuperus N, van den Anker JN. Newborn hearing screening: tobramycin and vancomycin are not risk factors for hearing loss. J Pediatr. 2003;142:41-6.

95. de Hoog M, van Zanten GA, Hoeve LJ, Blom AM, van den Anker JN. A pilot case control follow-up study on hearing in children treated with tobramycin in the newborn period. Int J Pediatr Otorhinolaryngol. 2002;65:225-32.

96. Johnson RF, Cohen AP, Guo Y, Schibler K, Greinwald JH. Genetic mutations and aminoglycoside-induced ototoxicity in neonates. Otolaryngol Head Neck Surg. 2010;142:704-7.

97. Robertson CM, Tyebkhan JM, Peliowski A, Etches PC, Cheung PY. Ototoxic drugs and sensorineural hearing loss following severe neonatal respiratory failure. Acta Paediatr. 2006:95:214-23.

98. Setiabudy R, Suwento R, Rundjan L, Yasin FH, Louisa M, Dwijayanti A, et al. Lack of a relationship between the serum concentration of aminoglycosides and ototoxicity in neonates. Int J Clin Pharmacol Ther. 2013;51:401-6.

99. Naeimi M, Maamouri G, Boskabadi H, Golparvar S, Taleh M, Esmaeeli H, et al. Assessment of aminoglycoside-induced hearing impairment in hospitalized neonates by TEOAE. Indian J Otolaryngol Head Neck Surg. 2009;61:256-61.

100. Vella-Brincat JW, Begg EJ, Robertshawe BJ, Lynn AM, Borrie TL, Darlow BA. Are gentamicin and/or vancomycin associated with ototoxicity in the neonate? A retrospective audit. Neonatology. 2011;100:186-93.

101. Estivill X, Govea N, Barcelo E, Badenas C, Romero E, Moral L, et al. Familial progressive sensorineural deafness is mainly due to the mtDNA A1555G mutation and is enhanced by treatment of aminoglycosides. Am J Hum Genet. 1998;62:27-35.
102. Brown DR, Watchko JF, Sabo D. Neonatal sensorineural hearing loss associated with furosemide: a case-control study. Dev Med Child Neurol. 1991;33:816-23.

103. Cheung PY, Robertson CM. Sensorineural hearing loss in survivors of neonatal extracorporeal membrane oxygenation. Pediatr Rehabil. 1997;1:127-30.

104. Fligor BJ, Neault MW, Mullen CH, Feldman HA, Jones DT. Factors associated with sensorineural hearing loss among survivors of extracorporeal membrane oxygenation therapy. Pediatrics. 2005;115:1519-28.

105. Murray M, Nield T, Larson-Tuttle C, Seri I, Friedlich P. Sensorineural hearing loss at 9-13 years of age in children with a history of neonatal extracorporeal membrane oxygenation. Arch Dis Child Fetal Neonatal Ed. 2011;96:F128-132.

106. Danzer E, Kim SS. Neurodevelopmental outcome in congenital diaphragmatic hernia: Evaluation, predictors and outcome. World J Clin Pediatr. 2014;3:30-6.

107. Dennett KV, Fligor BJ, Tracy S, Wilson JM, Zurakowski D, Chen C. Sensorineural hearing loss in congenital diaphragmatic hernia survivors is associated with postnatal management and not defect size. J Pediatr Surg. 2014;49:895-9.

108. Morando C, Midrio P, Gamba P, Filippone M, Sgro A, Orzan E. Hearing assessment in high-risk congenital diaphragmatic hernia survivors. Int $J$ Pediatr Otorhinolaryngol. 2010;74:1176-9.

109. Wilson MG, Riley P, Hurteau AM, Baird R, Puligandla PS. Hearing loss in congenital diaphragmatic hernia $(\mathrm{CDH})$ survivors: is it as prevalent as we think? J Pediatr Surg. 2013;48:942-5.

110. Inhaled nitric oxide in term and near-term infants: neurodevelopmental follow-up of the neonatal inhaled nitric oxide study group (NINOS). J Pediatr. 2000, 136:611-617

111. Konduri GG, Vohr B, Robertson C, Sokol GM, Solimano A, Singer J, et al. Early inhaled nitric oxide therapy for term and near-term newborn infants with hypoxic respiratory failure: neurodevelopmental follow-up. J Pediatr. 2007;150:235-40. 240.e231

112. Bao X, Wong V. Brainstem auditory-evoked potential evaluation in children with meningitis. Pediatr Neurol. 1998;19:109-12.

113. Edmond K, Clark A, Korczak VS, Sanderson C, Griffiths UK, Rudan I. Global and regional risk of disabling sequelae from bacterial meningitis: a systematic review and meta-analysis. Lancet Infect Dis. 2010;10:317-28.

114. Stevens JP, Eames M, Kent A, Halket S, Holt D, Harvey D. Long term outcome of neonatal meningitis. Arch Dis Child Fetal Neonatal Ed. 2003;88:F179-184.

115. Bolisetty S, Dhawan A, Abdel-Latif M, Bajuk B, Stack J, Lui K. Intraventricular hemorrhage and neurodevelopmental outcomes in extreme preterm infants. Pediatrics. 2014;133:55-62

116. Futagi $Y$, Toribe $Y$, Ogawa K, Suzuki Y. Neurodevelopmental outcome in children with intraventricular hemorrhage. Pediatr Neurol. 2006;34:219-24.

117. O'Shea TM, Allred EN, Kuban KC, Hirtz D, Specter B, Durfee S, et al. Intraventricular hemorrhage and developmental outcomes at 24 months of age in extremely preterm infants. J Child Neurol. 2012;27:22-9.

118. Hashemipour M, Hovsepian S, Hashemi M, Amini M, Kelishadi R, Sadeghi S. Hearing impairment in congenitally hypothyroid patients. Iran J Pediatr. 2012;22:92-6.

119. Léger J, Ecosse E, Roussey M, Lanoë JL, Larroque B. Subtle health impairment and socioeducational attainment in young adult patients with congenital hypothyroidism diagnosed by neonatal screening: a longitudinal population-based cohort study. J Clin Endocrinol Metab. 2011;96:1771-82.

120. Lichtenberger-Geslin L, Dos Santos S, Hassani Y, Ecosse E, Van Den Abbeele T, Léger J. Factors associated with hearing impairment in patients with congenital hypothyroidism treated since the neonatal period: a national population-based study. J Clin Endocrinol Metab. 2013;98:3644-52.

121. Barrenäs ML, Jonsson $B$, Tuvemo T, Hellström PA, Lundgren M. High risk of sensorineural hearing loss in men born small for gestational age with and without obesity or height catch-up growth: a prospective longitudinal register study on birth size in 245,000 Swedish conscripts. J Clin Endocrinol Metab. 2005;90:4452-6.

122. Mancini PC, Durrant JD, Starling AL, lório MC. Children with phenylketonuria treated early: basic audiological and electrophysiological evaluation. Ear Hear. 2013;34:236-44.

123. Martines F, Salvago P, Bentivegna D, Bartolone A, Dispenza F, Martines E. Audiologic profile of infants at risk: experience of a Western Sicily tertiary care centre. Int J Pediatr Otorhinolaryngol. 2012;76:1285-91.

124. Van Kerschaver E, Boudewyns AN, Declau F, Van de Heyning PH, Wuyts FL. Socio-demographic determinants of hearing impairment studied in 103,835 term babies. Eur J Public Health. 2013;23:55-60. 
125. Guyatt GH, Oxman AD, Sultan S, Glasziou P, Akl EA, Alonso-Coello P, et al. GRADE guidelines: 9. Rating up the quality of evidence. J Clin Epidemiol. 2011;64:1311-6.

126. Guyatt $G H$, Oxman AD, Schünemann HJ, Tugwell $P$, Knottnerus A. GRADE guidelines: a new series of articles in the Journal of Clinical Epidemiology. J Clin Epidemiol. 2011;64:380-2.

127. Schünemann HJ, Oxman AD, Brozek J, Glasziou P, Jaeschke R, Vist GE, et al. Grading quality of evidence and strength of recommendations for diagnostic tests and strategies. BMJ. 2008;336:1106-10.

128. Verleye L DA, Gailly J, Robays J. Dépistage du cancer du sein: comment identifier les femmes exposées à un risque accru - Quelles techniques d'imagerie utiliser? Good Clinical Practice (GCP). Centre fédéral d'expertise des soins de santé (KCE) edition. Brussels. 2011. https://kce.fgov.be/sites/ default/files/page_documents/KCE_172B_depistage_du_cancer.pdf. Accessed 16 Jun 2014

\section{Submit your next manuscript to BioMed Central and take full advantage of:}

- Convenient online submission

- Thorough peer review

- No space constraints or color figure charges

- Immediate publication on acceptance

- Inclusion in PubMed, CAS, Scopus and Google Scholar

- Research which is freely available for redistribution 